\title{
Effect of secretin, pancreozymin OP-CCK, and glucagon on bile flow and bile lipid secretion in rats
}

\author{
K W ROMANSKI AND W J BOCHENEK \\ From the Department of Animal Physiology, Institute of Physiological Sciences, Academy of Agriculture, \\ Wroclaw, and Department of Cardiology, Institute of Internal Medicine, Medical Academy, Wroclaw, \\ Poland
}

SUMMARY Rats equipped with biliary, duodenal, and vena cava cannulae and supplemented with $\mathrm{Na}$ taurocholate received 4 hour infusions of gastrointestinal hormones. Boots secretin increased bile flow by $63 \%$ and bile acid, cholesterol, and phospholipid output by 75,96 , and $73 \%$ respectively. This stimulatory effect on bile flow and bile acid secretion was observed also in the four hour postinfusion period. Kabi secretin had practically no effect on bile secretion. Boots pancreozymin stimulated bile flow by $45 \%$ and to some extent also stimulated bile acid output. $\mathrm{OP}-\mathrm{CCK}$ and glucagon stimulated mainly bile flow rate.

Bile formation is a complex process comprised of the secretory activity of hepatocytes and bile ducts. Regulatory mechanisms of bile secretion are not fully understood and it is believed that they are mainly of neurohumoral nature. ${ }^{1}$ One of the strongest stimuli of bile secretion are bile salts which are secreted into the canaliculi by the carrier mediated active process, and a linear relationship exists between bile salt secretory rate and bile flow. ${ }^{2} 3$ In addition to bile salt dependent secretion there is also bile salt independent canalicular secretion which is believed to be related to the sodium pump. More distally, mechanisms of bile secretion are controlled by gastrointestinal hormones of which secretin is the most active. Glucagon which is structurally related to secretin is five times less active ${ }^{4}$ Cholecystokinin (CCK) also stimulates bile secretion but its choleretic potency is less than that of secretin, but greater than that of gastrin. ${ }^{5}$ Gastrointestinal hormones acting at the ductular level are thought to affect mainly biliary secretion of electrolytes. ${ }^{67}$ Some, reports indicate, however, that these hormones can also stimulate canalicular secretion as suggested by increase in the biliary clearance of erythritol. ${ }^{89}{ }^{10}$ Gardiner and Small ${ }^{11}$ studying the effects of secretin and CCK on bile secretion in Rhesus monkeys observed dose related increases in

Address for correspondence: Dr W J Bocheneck. Division of Gastroenterology. Department of Medicine. Albany Medical College. Albany. New York 12208. USA.

Received for publication 1 November 1982 the secretion of bile salts and cholesterol but not of phospholipids. Administration of these hormones did not increase bile acid pool size but decreased their enterohepatic circulation time. The fact that in the latter study not only bile salt but also cholesterol secretion was altered, might indicate that indeed some hormones can affect hepatocyte function.

In view of existing controversies it was decided to study the effect of prolonged stimulation with secretin, CCK and glucagon, on bile secretion in rats under conditions of interrupted enterohepatic circulation of bile salts, and artificially controlled bile acid pool. In such a model, changes in biliary lipid output would indicate a direct effect of the hormones on canalicular bile secretion and thus on hepatocyte function.

\section{Methods}

Forty male Wistar rats weighing 200-350 g were used in the study. After a 24 hour fast they were operated under ether anaesthesia. The common bile duct was cannulated with polyethylene tubing (PE 50), a duodenal cannula was introduced through the fundus of the stomach to preserve integrity of the duodenum, and an intravenous cannula was inserted into the inferior vena cava. After surgery, the rats were housed in modified Bollman cages.

Immediately postsurgery, and continuing throughout the entire experiment, animals were infused intraduodenally with $10 \mathrm{mmol}$ sodium tauro- 
cholate (Calbiochem, San Diego, CA) in $67 \mathrm{mmol}$ phosphate buffer $\mathrm{pH} 6.5$ at the rate of $0.53 \mathrm{ml} / \mathrm{h}$, and intravenously with $0.15 \mathrm{M} \mathrm{NaCl}$ at the rate of 0.5 $\mathrm{ml} / \mathrm{h}$. Water was available ad libitum. Eighteen to 20 hours were allowed for recovery after the surgery. During the following 12 hours, bile was collected in three 4 hour intervals, $18-22,22-26$, and $26-30$ hours of the experiment.

Gastrointestinal hormones made up in $0.15 \mathrm{M}$ sodium chloride were infused intravenously between 22-26 hours of the experiment. The following hormone preparations were used: secretin (Boots) $1.33 \mathrm{U} * / \mathrm{kg} / \mathrm{min}$, secretin-Kabi $0.017 \mathrm{CU}+/ \mathrm{kg} / \mathrm{min}$, pancreozymin (Boots) $1 \mathrm{U}^{*} / \mathrm{kg} / \mathrm{min}$, pancreozymin octapeptide (OP-CCK-Squibb Inst.) $0.036 \mu \mathrm{g} / \mathrm{kg} /$ min, glucagon (Novo) $9 \mu \mathrm{g} / \mathrm{kg} / \mathrm{min}$.

Bile samples, after determination of their volume, were stored at $-20^{\circ} \mathrm{C}$ for up to two months. Total bile acids were determined enzymatically by the hydroxysteroid dehydrogenase method using Sterognost-3 $\alpha$-Pho-test. Bile lipids were extracted using the method of Folch et $a l,{ }^{12}$ and lipid phosphorus $^{13}$ and cholesterol ${ }^{14}$ were determined.

\section{Results}

All hormones studied, with the exception of Kabi secretin, significantly increased the bile flow during the period of hormonal infusion (Table 1). Boots secretin gave the strongest response increasing bile flow by $63 \%(\mathrm{p}<0.001)$, and maintained an increased bile flow even in the four hour posthormone infusion period. Boots pancreozymin stimulated bile flow equally, but only during its administration. OP-CCK was the weakest stimulant, and during the infusion of Kabi secretin, volume of

* Crick, Harper, and Raper units.

† Trade name for Gastrointestinal Hormone Laboratory (GIH) Secretin. CU clinical unit.

Table 1 Bile flow

\begin{tabular}{|c|c|c|c|c|}
\hline \multirow{2}{*}{$\begin{array}{l}\text { Hormone } \\
\text { administered }\end{array}$} & \multirow{2}{*}{$\begin{array}{l}\text { Rats } \\
\text { (no.) }\end{array}$} & \multicolumn{3}{|c|}{ Hours of experiment } \\
\hline & & $18-22$ & $22-26$ & $26-30$ \\
\hline Control & 9 & $0.7 \pm 0.12$ & $0.72 \pm 0.11$ & $0.69 \pm 0.12$ \\
\hline Secretin (Boots) & 6 & $0.68 \pm 0.1$ & $1 \cdot 1 \pm 0 \cdot 1 \dagger$ & $0.76 \pm 0.12^{*}$ \\
\hline Secretin (Kabi) & 6 & $0.86 \pm 0.21$ & $0.78 \pm 0.17$ & $0.71 \pm 0.15$ \\
\hline Pancreozymin & 6 & $0.76 \pm 0.03$ & $1 \cdot 1 \pm 0.08 \dagger$ & $0.82 \pm 0.08$ \\
\hline OP-CCK & 5 & $0.7 \pm 0.06$ & $0.77 \pm 0.08^{*}$ & $0.68 \pm 0.04$ \\
\hline Glucagon & 8 & $0.71 \pm 0.15$ & $0.83 \pm 0.17 \dagger$ & $0.71 \pm 0.12$ \\
\hline
\end{tabular}

Bile flow in $\mathrm{ml} / \mathrm{h} \pm 1 \mathrm{SD}$.

$\mathrm{p}$ Calculated in comparison with the $18-22 \mathrm{~h}$ period. $* \mathrm{p}<0.05$. $+\mathrm{p}<0.001$.
Table 2 Bile acid excretion

\begin{tabular}{lllll}
\hline \multirow{5}{*}{$\begin{array}{l}\text { Hormone } \\
\text { administered }\end{array}$} & & $18-22$ & $22-26$ & $26-30$ \\
\cline { 2 - 5 } Control & c & $11 \cdot 4 \pm 4 \cdot 4$ & $12 \cdot 0 \pm 3 \cdot 6$ & $12 \cdot 4 \pm 3 \cdot 2$ \\
& o & $31 \cdot 1 \pm 10 \cdot 8$ & $34 \cdot 3 \pm 10 \cdot 4$ & $33 \cdot 8 \pm 8 \cdot 5$ \\
Secretin (Boots) & c & $11 \cdot 1 \pm 4 \cdot 0$ & $11 \cdot 6 \pm 3 \cdot 2$ & $17 \cdot 4 \pm 11 \cdot 1$ \\
& o & $28 \cdot 8 \pm 10 \cdot 1$ & $50 \cdot 6 \pm 16 \cdot 7^{*}$ & $47 \cdot 8 \pm 18 \cdot 4^{*}$ \\
Secretin (Kabi) & c & $9 \cdot 5 \pm 4 \cdot 8$ & $10 \cdot 8 \pm 5 \cdot 2$ & $11 \cdot 2 \pm 7 \cdot 4$ \\
& o & $37 \cdot 3 \pm 7 \cdot 8$ & $41 \cdot 9 \pm 9 \cdot 4$ & $41 \cdot 7 \pm 11 \cdot 5$ \\
Pancreozymin & c & $13 \cdot 6 \pm 7 \cdot 0$ & $12 \cdot 0 \pm 4 \cdot 3$ & $10 \cdot 0 \pm 4 \cdot 9$ \\
& o & $34 \cdot 5 \pm 18 \cdot 1$ & $41 \cdot 5 \pm 11 \cdot 3$ & $26 \cdot 0 \pm 10 \cdot 5$ \\
OP-CCK & c & $9 \cdot 0 \pm 3 \cdot 1$ & $10 \cdot 9 \pm 1 \cdot 7$ & $11 \cdot 6 \pm 4 \cdot 6$ \\
& o & $21 \cdot 3 \pm 6 \cdot 4$ & $28 \cdot 6 \pm 1 \cdot 7$ & $27 \cdot 4 \pm 7 \cdot 7$ \\
Glucagon & c & $10 \cdot 3 \pm 4 \cdot 9$ & $8 \cdot 1 \pm 2 \cdot 6$ & $9 \cdot 7 \pm 2 \cdot 9$ \\
& o & $29 \cdot 1 \pm 14 \cdot 3$ & $25 \cdot 9 \pm 12 \cdot 4$ & $26.4 \pm 10 \cdot 3$ \\
\hline
\end{tabular}

Bile acid concentration in $\mu \mathrm{mol} / \mathrm{ml}$ and bile acid output in $\mu \mathrm{mol} / \mathrm{kg} / \mathrm{h}$. Values represent mean $\pm 1 \mathrm{SD}$.

* See Table 1. c Concentration. o Output.

secreted bile actually decreased.

Bile acid output increased significantly only during infusion of Boots secretin (Table 2). It averaged $75 \%$ over the control period and was related mainly to increased rate of bile flow with only little change in bile acid concentration. Bile acid output also remained raised in the posthormone infusion period. Pancreozymin stimulated bile acid output only during hormonal infusion. Because of the wide scatter of values no statistical significance was reached. The other hormone preparations had little or no affect on bile acid output. Boots secretin also increased cholesterol output, which almost doubled (Table 3). In the postinfusion period, cholesterol output decreased, but remained raised as compared with the control period. None of the

Table 3 Cholesterol excretion

\begin{tabular}{|c|c|c|c|c|}
\hline \multirow{2}{*}{$\begin{array}{l}\text { Hormone } \\
\text { administered }\end{array}$} & & \multicolumn{3}{|c|}{ Hours of experiment } \\
\hline & & $18-22$ & $22-26$ & $26-30$ \\
\hline \multirow[t]{2}{*}{ Control } & c & $0.92 \pm 0.19$ & $0.92 \pm 0.29$ & $0 \cdot 87 \pm 0.22$ \\
\hline & o & $2 \cdot 59 \pm 0 \cdot 86$ & $2 \cdot 6 \pm 0 \cdot 7$ & $2 \cdot 34 \pm 0 \cdot 56$ \\
\hline \multirow[t]{2}{*}{ Secretin (Boots) } & c & $1.09 \pm 0.38$ & $1 \cdot 36 \pm 0 \cdot 4$ & $1.22 \pm 0.34$ \\
\hline & o & $2 \cdot 81 \pm 0 \cdot 86$ & $5 \cdot 5 \pm 1 \cdot 13 \dagger$ & $3.44 \pm 0.67$ \\
\hline \multirow[t]{2}{*}{ Secretin (Kabi) } & c & $0.51 \pm 0.17$ & $0 \cdot 4 \pm 0 \cdot 11$ & $0.38 \pm 0.09$ \\
\hline & o & $2 \cdot 1 \pm 0 \cdot 53$ & $1 \cdot 5 \pm 0 \cdot 24$ & $1 \cdot 3 \pm 0 \cdot 12$ \\
\hline \multirow{2}{*}{ Pancreozymin } & c & $0.98 \pm 0.27$ & $0.74 \pm 0.18$ & $1.02 \pm 0.26$ \\
\hline & o & $2.49 \pm 0.71$ & $2 \cdot 6 \pm 0.64$ & $2 \cdot 81 \pm 1 \cdot 0$ \\
\hline \multirow[t]{2}{*}{ OP-CCK } & c & $0.74 \pm 0.1$ & $0.73 \pm 0.06$ & $0.87 \pm 0.15$ \\
\hline & 0 & $1.78 \pm 0.35$ & $1.94 \pm 0.3$ & $2.07 \pm 0.49$ \\
\hline \multirow[t]{2}{*}{ Glucagon } & c & $1 \cdot 21 \pm 0 \cdot 12$ & $1 \cdot 02 \pm 0.27$ & $1 \cdot 08 \pm 0.3$ \\
\hline & o & $3 \cdot 22 \pm 0.75$ & $3 \cdot 15 \pm 1 \cdot 15$ & $2 \cdot 88 \pm 0 \cdot 89$ \\
\hline
\end{tabular}

Cholesterol concentration in $\mu \mathrm{mol} / \mathrm{ml}$ and cholesterol output in $\mu \mathrm{mol} / \mathrm{kg} / \mathrm{h}$.

† See Table 1. c Concentration. o Output. 
Table 4 Phospholipid excretion

\begin{tabular}{|c|c|c|c|c|}
\hline \multirow{2}{*}{$\begin{array}{l}\text { Hormone } \\
\text { administered }\end{array}$} & & \multicolumn{3}{|c|}{ Hours of experiment } \\
\hline & & $18-22$ & $22-26$ & $26-30$ \\
\hline \multirow[t]{2}{*}{ Control } & c & $1 \cdot 6 \pm 1 \cdot 2$ & $1 \cdot 7 \pm 1 \cdot 0$ & $2 \cdot 1 \pm 1 \cdot 5$ \\
\hline & o & $4 \cdot 4 \pm 2.9$ & $4 \cdot 8 \pm 3 \cdot 0$ & $5 \cdot 5 \pm 3 \cdot 5$ \\
\hline \multirow[t]{2}{*}{ Secretin (Boots) } & c & $2 \cdot 5 \pm 1 \cdot 1$ & $2 \cdot 5 \pm 1 \cdot 2$ & $2 \cdot 5 \pm 1 \cdot 1$ \\
\hline & o & $6 \cdot 5 \pm 2.9$ & $10 \cdot 4 \pm 5 \cdot 8^{*}$ & $7 \cdot 0 \pm 2 \cdot 5$ \\
\hline \multirow[t]{2}{*}{ Secretin (Kabi) } & c & $1 \cdot 5 \pm 1 \cdot 1$ & $1 \cdot 4 \pm 1 \cdot 1$ & $1 \cdot 5 \pm 1 \cdot 1$ \\
\hline & o & $5 \cdot 5 \pm 3 \cdot 2$ & $4 \cdot 6 \pm 3 \cdot 0$ & $4 \cdot 6 \pm 2 \cdot 6$ \\
\hline \multirow[t]{2}{*}{ Pancreozymin } & c & $1.6 \pm 0.9$ & $1 \cdot 1 \pm 0.6$ & $1 \cdot 6 \pm 0 \cdot 6$ \\
\hline & o & $4 \cdot 1 \pm 2 \cdot 7$ & $3 \cdot 8 \pm 2 \cdot 3$ & $4 \cdot 4 \pm 1 \cdot 4$ \\
\hline \multirow[t]{2}{*}{ OP-CCK } & c & $2 \cdot 1 \pm 1 \cdot 6$ & $1 \cdot 6 \pm 1 \cdot 2$ & $1.8 \pm() \cdot 8$ \\
\hline & o & $4 \cdot 9 \pm 3 \cdot 6$ & $4 \cdot 1 \pm 2 \cdot 7$ & $4 \cdot 1 \pm 1 \cdot 7$ \\
\hline \multirow[t]{2}{*}{ Glucagon } & c & $2 \cdot 4 \pm 1 \cdot 6$ & $1.8 \pm 0.9$ & $1 \cdot 8 \pm 1 \cdot 2$ \\
\hline & o & $6 \cdot 2 \pm 4 \cdot 2$ & $5 \cdot 4 \pm 2 \cdot 8$ & $4 \cdot 7 \pm 2 \cdot 8$ \\
\hline
\end{tabular}

Phospholipid concentration in $\mu \mathrm{mol} / \mathrm{ml}$ and phospholipid output in $\mu \mathrm{mol} / \mathrm{h} / \mathbf{k g}$.

* See Table 1. c Concentration. o Output.

other hormones stimulated cholesterol secretion.

Secretion of biliary phospholipids increased by $73 \%$ during Boots secretin infusion, but was only minimally affected by other hormones (Table 4).

\section{Discussion}

The results of this study confirm the findings of other authors that major gastrointestinal hormones participate in the regulation of bile secretion. ${ }^{111} 16$ With the sole exception of Kabi secretin, all hormones increased bile flow rates. Boots secretin and pancreozymin preparations gave quantitatively the strongest stimulation while OP-CCK and glucagon were weaker stimulants.

Of the preparations studied, only Boots secretin and pancreozymin stimulated bile acid output, and secretin in addition stimulated cholesterol output. By contrast, the more highly purified Kabi secretin and OP-CCK, had little or no effect on bile flow and bile lipid content. The lack of activity of GIH secretin in the rat has been also observed by Petersen and Grossman. ${ }^{15}$ Rutishauser ${ }^{16}$ who studied both secretin preparations also found GIH secretin much less potent, and concluded that the stimulating properties of Boots secretin are most probably due to contaminants of this preparation. Parallel increases of bile acid and cholesterol outputs indicate that Boots secretin has a direct hepatocytic stimulatory effect. Similar stimulation of bile acid secretion by Boots secretin had also been observed in the perfused pig liver ${ }^{17}$ and calf liver ${ }^{18}$ preparations. Unlike in Gardiner and Small's study, ${ }^{11}$ stimulatory effects of this secretin preparation cannot be attributed to more rapid enterohepatic circulation of bile acids as the animals studied had complete diversion of bile, and their bile acid pool had been maintained by enterol infusion of exogenous bile salts.

Comparison of the results of various studies is difficult because of differences in species and specificities of experimental models and hormone preparations. This study indicates that although the gastrointestinal hormones studied had choleretic activity in the rat, the purer or synthetic hormones did not affect biliary lipid output, thus, it is unlikely that they stimulate canalicular phases of bile secretion. Stimulation of sterol output by Boots secretin and pancreozymin is most probably not related to these hormones but to some unidentified contaminants of these preparations. We examined the bile acid content of the particular batch of Boots secretin used, and found it negligible. The strongest choleretic effect of both Boots hormone preparations can be attributed partly to their stimulatory effect on bile acid secretion.

The authors are grateful for the donation of reagents and hormone preparations for this study by Nyegaard and $\mathrm{Co}, \mathrm{A} / \mathrm{S}$, Oslo, Norway - sterognost$3 \alpha$-Pho-test, The Boots Co Ltd, Nottingham, England - secretin and pancreozymin, The Squibb Institute for Medical Research, Princeton, NJ, USA, - synethetic OP-CCK/Sincalide.

\section{References}

1 Jones RS, Meyers WC. Regulation of hepatic biliary secretion. Ann Rev Physiol 1979; 41: 67-82.

2 Boyer JL. Candicular bile formation in the isolated perfused rat liver. Am J Physiol 1971; 221: 1156-63.

3 Klaassen CD. Comparison of the choleretic properties of bile acids. Eur J Pharmacol 1973; 23: 270-5.

4 Jones RS, Brooks FP. The role of pyloric antrum in choleresis after insulin and feeding. Am J Physiol 1967; 213: 1406-11.

5 Jones RS, Grossman MI. The choleretic effects of cholecystokinin (CCK), gastrin II, and caerulein in the dog. Am J Physiol 1970; 219: 1014-8.

6 Jones RS, Geist RE, Hall AD. The choleretic effects of glucagon and secretin in the dog. Gastroenterology 1971; 60: 64-8.

7 Thulin L. The choleretic effect of pure natural cholecystokinin in dogs. Acta Chir Scand 1973; 139: 635-40.

8 Barnhart JL, Combes B. Erythritol and mannitol clearances with taurocholate and secretin induced choleresis. Am J Physiol 1978; 234: 146-56.

9 Shaw RA, Jones RS. The choleretic action of cholecystokinin and cholecystokinin octapeptide in dogs. Surgery 1978; 84: 622-5. 
10 Russell TR, Searle GL, Jones RS. The choleretic mechanisms of sodium taurocholate, secretin, and glucagon. Surgery 1975; 77: 498-504.

11 Gardiner BN, Small DM. The effects of secretin (Sec) and cholecystokinin (CCK) on secretion of bile salts (BS) and biliary lipids. Clin Res 1972; $20: 454$.

12 Folch J, Lees M, Sloane-Stanley GH. A simple method for the isolation and purification of total lipids from animal tissues. J Biol Chem 1957; 226: 497-509.

13 Bartlett GR. Phosphorus assay in column chromatography. J Biol Chem 1959; 234: 466-8.

14 Zak B. A simple, rapid microtechnique for serum total cholesterol. Am J Clin Pathol 1957; 27: 583-8.
15 Petersen H, Grossman MI. Pancreatic exocrine secretion in anaesthetized and conscious rats. Am J Physiol 1977; 233: E530-6.

16 Rutishauser SCB. An analysis of the reported choleretic effect of secretin in the rat. J Physiol (Lond) 1976; 257: 59P.

17 Gordon EM, Douglas MC, Jablonski P, Owen JA, Sali A, Watts J McK. Gastroduodenal hormones and bile-secretion studies in the isolated perfused pig liver. Surgery 1972; 72: 708-21.

18 Pissidis AG, Bombeck CT, Merchant F, Nyhus LM. Hormonal regulation of bile secretion: a study in the isolated, perfused liver. Surgery 1969; 66: 1075-84. 